\title{
Continuing Life Test of a Xenon Hollow Cathode for a Space Plasma Contactor
}

Timothy R. Sarver-Verhey

NYMA, Inc.

Engineering Services Division

Brook Park, Ohio

November 1994

Prepared for

Lewis Research Center

Under Contract NAS3-27186

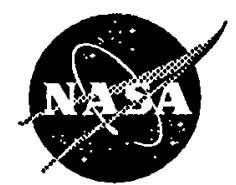

National Aeronautics and Space Administration 


\title{
Continuing Life Test of a Xenon Hollow Cathode for a Space Plasma Contactor
}

\author{
Timothy R. Sarver-Verhey \\ NYMA, Inc. \\ Engineering Services Division \\ Brook Park, Ohio 44142
}

\begin{abstract}
Implementation of a hollow cathode plasma contactor for charge control on the Space Station has required validation of long-life hollow cathodes. A test series of hollow cathodes and hollow cathode plasma contactors was initiated as part of the plasma contactor development program. An on-going wear-test of a hollow cathode has demonstrated cathode operation in excess of 10,000 hours with small changes in operating parameters. The discharge has experienced 10 shutdowns during the test, all of which were due to test facility failures or expellant replenishment. In all cases, the cathode was re-ignited at approximately 42 volts and resumed typical operation. This test represents the longest demonstrated stable operation of a high current ( $>1$ A) xenon hollow cathode reported to date.
\end{abstract}

\section{Introduction}

The decision to baseline a plasma contacting device on the International Space Station Alpha (ISSA) was reached recently. ${ }^{1}$ This plasma contactor will provide a connection from station structure to the surrounding space plasma and effectively prevent a build-up of potentially deleterious electrical charge on the Space Station. $^{2}$ Operational requirements for the plasma contactor set out at the beginning of this program were to provide a neutralization current of between 0.75 to 10.0 A of electron current, over approximately onethird of the orbital period of approximately 90 minutes. The plasma contactor system is required to perform for two years on-orbit for a total cathode operation time of 17,500 hours. To meet these requirements, a reliable, long-life electron emitter for the plasma contactor is needed.

A hollow cathode-based configuration was selected as the electron emitter due to its successful application to ion thruster plasma production and beam neutralization. In these applications, a hollow cathode typically is a high-temperature metal tube with or without a restrictor at the downstream end. A low work function emitting insert is positioned in the tube. This emitter has been either a roll of tantalum foil coated with a barium-strontium compound or a porous tungsten cylinder insert impregnated with $\mathrm{BaO}-\mathrm{CaO}$ $\mathrm{Al}_{2} \mathrm{O}_{3}$-based compounds. ${ }^{3} \mathrm{~A}$ heater mounted on the cathode tube is used to raise the temperature of the emitter to enhance electron emission for discharge ignition. The restrictor plate on the downstream end of the cathode tube increases the local pressure at the emitter which in turn reduces the voltage requirements for the electrical discharge. Once the discharge has been initiated and a stable discharge has been established, ion bombardment of the emitter sustains the temperature without use of the heater.

In the United States ion propulsion program, mercury vapor was used extensively in hollow cathodes, including those for the Space Electric Rocket Test (SERT) II ${ }^{4}$ the $8-\mathrm{cm}$ ion thruster system, ${ }^{5}$ the Ion Auxiliary Propulsion Subsystem (IAPS), ${ }^{6}$ and the Solar Electric Propulsion Subsystem (SEPS) ${ }^{7}$ development programs. Mercury was also the propellant used in the United Kingdom's thruster development program, ${ }^{8}$ West Germany's Radio-frequency Ion Thruster (RIT10) thruster development program, ${ }^{9}$ and the Japanese ETS-III propulsion system development program. ${ }^{10}$ However, due to spacecraft operational and environmental concerns, an alternative to mercury was sought.

Since 1980, inert gases have become the propellant of choice for electrostatic ion thrusters. While long-life operation of cathodes with mercury expellant has been demonstrated, ${ }^{11,12}$ the testing database with inert gases remains small. Additionally, within that experience base, there have been several instances of performance degradation and cathode failure. These failures included cathode orifice erosion, $13,14,15$ cathode body tube fracturing and swelling, ${ }^{16}$ and degradation of performance and internal surfaces of the hollow cathode. ${ }^{17,18,19}$ Examples of body tube cracking and anomalous material formation are shown in Figures 1 and 2 , respectively.

To date, there have been five reports of hollow cathode extended testing operating on inert gases at emission currents of several amperes for longer than 1,000 hours. Table 1 summarizes the operating conditions of these tests. First, a xenon ion propulsion subsystem was operated at $1.4 \mathrm{~kW}$ for 4,350 hours. ${ }^{14}$ The main discharge hollow cathode had an intermediate keeper electrode and operated at a total emission current of 7.4 A (keeper current of $1.0 \mathrm{~A}$, discharge emission current of $6.4 \mathrm{~A}$ ). During the test, the main cathode discharge and keeper voltages averaged $27.2 \mathrm{~V}$ and $15.2 \mathrm{~V}$, respectively. The problems reported included the closure of the main discharge cathode orifice at approximately 700 hours into the wear-test. This cathode was then replaced with 
a larger-orificed cathode. The new main discharge cathode was used for the remainder of the test and exhibited negligible change in orifice plate condition. The neutralizer operated at nominal keeper and coupling voltages of 18.0 and $24.0 \mathrm{~V}$, respectively, and a total emission current of $3.45 \mathrm{~A}$. The post-test condition of the neutralizer exhibited negligible changes.

Second, a 5000 hour steady-state test of a xenon hollow cathode in an ion thruster simulator was conducted at an emission current of $25 \mathrm{~A} .{ }^{19}$ In that test, several undesirable phenomena were experienced. First, the discharge voltage varied from a maximum of 21.0 volts to a minimum of 12.0 , with a nominal voltage of approximately $17.5 \mathrm{~V}$. Second, the ignition voltage varied from a minimum of $18.0 \mathrm{~V}$ to a maximum of more than $900 \mathrm{~V}$. Third, while the cathode orifice plate temperature averaged $1200^{\circ} \mathrm{C}$, the cathode insert brightness temperature was found to be substantially higher at $1500^{\circ} \mathrm{C}$. This operating temperature for the insert is considerably higher than recommended for these devices. ${ }^{3}$ Finally, the cathode orifice size increased during the test and substantial material deposition formed on the cathode insert surface.

Third, a 1,960-hour cyclic life-test of 14-cm xenon ion thruster was performed by Kitamura et al. at the National Aerospace Laboratory. ${ }^{20}$ This thruster incorporated two hollow cathodes for the main discharge and neutralizer with total emission currents of approximately $3.7 \mathrm{~A}$ and $0.5 \mathrm{~A}$, respectively. The discharge voltage of the main cathode varied from a low of $28.0 \mathrm{~V}$ to a maximum of $40.0 \mathrm{~V}$ with an average of approximately $35.0 \mathrm{~V}$. During this life test, the orifice size increased due to erosion. In addition, the neutralizer cathode experienced ignition difficulties during the life test and, by cycle 210 , the cathode insert and keeper electrode had to be replaced.

Fourth, a series of ion thruster life tests for the ETSVI Ion Engine program being performed at the National Space Development Agency of Japan and Mitsubishi Electric Corporation has been reported. ${ }^{21}$ The report described nine thruster system tests, each with a main and neutralizer cathode. Three tests of the nine tests had been completed at total run times of 9100,7200 , and 7100 hours respectively. The remainder of the tests were in progress and had accumulated between 4500 and 6200 hours. The completed tests were performed with one bread-board level system and two developmental model (DM) systems. The data provided in the report was for the DM tests, which had been run for 7200 and 7100 hours respectively. In each of these thrusters, the operating currents average $3.6 \mathrm{~A}$ and $0.9 \mathrm{~A}$ for main and neutralizer cathodes respectively. The main cathodes operated at a nominal voltage of $37.0 \mathrm{~V}$ for thrusters $\mathrm{DM} \# 1$ and DM \#2, while the neutralizers operated at nominal voltages of $19.0 \mathrm{~V}$ and $18.0 \mathrm{~V}$ for thrusters $D M \# 1$ and DM \#2, respectively. The only problem reported for these tests was performance degradation of neutralizer cathode from $\mathrm{DM} \# 2$ which was attributed to propellant contamination.

In addition to the thruster, endurance tests of main and neutralizer hollow cathodes were performed using bread-board, developmental, and prototype model hardware. Three main-neutralizer cathode pairs were performed for 8000 hours and 4000 cycles each. Results were given for the prototype model hardware which had completed a 8043 hour cyclic test. In that test, the main cathode operated at an average discharge voltage of $34.0 \mathrm{~V}$ and the neutralizer cathode operated at an average discharge voltage of $38.0 \mathrm{~V}$. The emission currents were 3.66 and $1.0 \mathrm{~A}$ for the main and neutralizer cathodes respectively. The only problematic behavior reported was variation in neutralizer cathode discharge voltage which changed from a maximum of $45.0 \mathrm{~V}$ to a minimum of $31.0 \mathrm{~V}$ over the course of the test. Both cathodes were operated for 4380 cycles of which the main cathode failed to ignite 11 times, and the neutralizer cathode failed to ignite 62 times.

Finally, Soulas ${ }^{22}$ reported the successful completion of a 2000 hour wear test of four hollow cathodes operating at emission currents of $10.0 \mathrm{~A}$ and at an average discharge voltage of $8.4 \mathrm{~V} \pm 0.4 \mathrm{~V}$. Ignition voltages for all 4 cathodes averaged $17.0 \mathrm{~V} \pm 2.8 \mathrm{~V}$ for the 6 starts that occurred during the test. These cathodes were operated concurrently in the same test facility under identical conditions. No performance degradation was observed during the test. In addition, post-test examination of the cathodes found negligible changes had occurred.

In 1989, a program was initiated at NASA-LeRC of extended tests of hollow cathodes ${ }^{18,23}$ to resolve the life-limiting problems which had been reported in earlier work. The primary cause suspected to be responsible for the observed performance and physical degradation was oxygen contamination that attacks the cathode surfaces, particularly the sensitive insert surfaces. ${ }^{18,23}$ There are three probable sources for oxygen contamination. First, the expellant gases (Xe, $\mathrm{Kr}, \mathrm{Ar}$ ) have residual contamination left over from the gas extraction process. Second, feed-system materials and components evolve contaminants either through leakage or by outgassing from internal surfaces. Third, excessive oxygen release from the cathode insert can occur if proper precautions are not taken. Contamination from the environment external to the cathode is neglected because it is not expected tobe able to reach the insert during operation due to sonic flow conditions at the cathode orifice. Environmental contamination able to reach the insert during the nonoperation periods will be removed during the pre-test preparations 
As part of this program, procedures were implemented and expellant feed-system fidelity improved to alleviate oxygen contamination. These changes resulted in improved cathode performance and reduced degradation of the internal cathode surfaces. In 1992, this test series has been expanded to meet the requirements of the Space Station plasma contactor application. ${ }^{2}$

In order to validate that cathode contamination can be alleviated by this approach and cathode life times improved, a test was prepared which incorporated all the procedures that had been developed for laboratory testing. For this test, a hollow cathode was set up in a dedicated vacuum facility, and operated at the maximum, steady-state emission current for the projected two year life of the plasma contactor. This paper will report the status of an on-going life-test of a xenon hollow cathode operating at a steady-state emission current of $12.0 \mathrm{~A}$ in a planar diode configuration.

\section{Experimental Apparatus}

\section{Hollow Cathode}

The hollow cathode, shown schematically in Fig. 3, consists of a molybdenum-compound tube with a tungsten orifice plate electron-beam welded to one end. A small orifice with a chamfer on the downstream surface was electron-discharge machined into this plate. The hollow cathode is similar to a laboratorymodel device that has been wear-tested extensively at NASA-LeRC for contamination studies and ion thruster testing, ${ }^{18,23}$ however the orifice diameter was decreased to accommodate the lower emission current requirements. The insert, a porous sintered tungsten cylinder impregnated with $4 \mathrm{BaO} \cdot \mathrm{CaO} \cdot \mathrm{Al}_{2} \mathrm{O}_{3}$, w as placed in the downstream end of the tube. Refractory metal electrical leads, attached to the rear of the insert, were spot-welded to the interior of the upstream end of the body tube. These leads provided electrical contact and maintained the position of the insert in the body tube.

A helical-wound sheathed heater used for cathode activation and ignition was friction-fitted on the outside of the body tube over the region occupied by the insert. ${ }^{17}$ Several layers of metal foil were tightly wrapped around the heater and spot-welded in place to reduce radiated power losses.

\section{Cathode-Anode Configuration}

This wear-test is being conducted with a planar anode, as shown in Fig. 4. The cathode is mounted on centerline of the test-port, supported by the ceramic insulator assembly that connected to the feed-system inlet. A compression fitting on the cathode (see Figure 3) joins the cathode assembly to the ceramic insulator assembly that thermally isolats it from the test assembly. The insulator and feed-line within the testport are all $0.64 \mathrm{~cm}$ diameter tubing. The anode consists of a $20.3 \mathrm{~cm}$ diameter molybdenum plate, mounted on test-port centerline with three support rods, positioned downstream from the plane of the cathode orifice plate. The anode plate is isolated from ground potential surfaces with three isolation mounts attached to the support rods. A small hole was drilled into the plate centerline to enable temperature measurement of the cathode orifice plate.

\section{Xenon Expellant Feed-system}

The expellant feed-system is shown schematically in Fig. 5. The feed-line is $0.64 \mathrm{~cm}$ diameter stainless-steel tubing. All tubing connections used ultra high vacuum metal gasket seals, except where transducer installation required polymer o-ring fittings. A gas purifier was installed upstream of the flow monitoring and control devices. The internal pressure of the feed-line is 170 $\mathrm{kPa}$ (10 psig) upstream of the flow control valve. A bypass line upstream of the flow control valve sped evacuation of the feed-system when pumping down from atmosphere. Additionally, a second bypass line was added upstream of the gas purifier during a shutdown at hour 3119 to speed evacuation from that portion of the feed-system.

\section{Xenon Expellant}

Research grade xenon (99.999\%) gas is used throughout the wear-test and parametric testing. According to vendor specifications for the xenon expellant, the maximum oxygen level (from $\mathrm{O}_{2}, \mathrm{H}_{2} \mathrm{O}$, $\mathrm{CO}_{2}$, and miscellaneous hydrocarbons) in the xenon is approximately $3.0 \mathrm{ppm}$. The xenon delivery pressure is $170 \mathrm{kPa}$ (10 psig).

\section{Power Supplies}

Two power supplies operate the hollow cathode as shown in the electrical schematic in Fig. 6. A 25 V, 15 A current-regulated supply provides the required power for the cathode heater during activation and starting. A $55 \mathrm{~V}, 20 \mathrm{~A}$, SCR-regulated power supply with a linear output stage provides the necessary voltage and current for both ignition and maintenance of the discharge. The cathode and all test-port surfaces are at facility ground while the anode plate is connected to the positive output of the discharge supply and electrically isolated from the test port. A $3.0 \mathrm{mH}$ inductor was included in the discharge circuit because it reduced power supply noise to less than $1 \%$ for both voltage and current.

\section{Instrumentation}

The static and dynamic behavior of the discharge voltage and current are monitored along with the xenon mass flow rate, the cathode temperatures, and facility and test port pressures (see Table I). The discharge 
voltage is measured both at the power supply and at the test flange to account for any line losses. The noise levels of the discharge voltage and emission current are measured at the test flange with a digital oscilloscope.

The cathode temperature is measured by two techniques. First, three type $\mathrm{R}(\mathrm{Pt}-13 \% \mathrm{Rh} / \mathrm{Pt})$ thermocouples were spot-welded (see Fig. 3) to the external surface of the cathode body tube immediately upstream of the orifice plate weld, immediately upstream of the heater coils, and at the compression fitting connection to the thermal isolator. Metal foil was spot-welded over the thermocouple junctions at the two downstream locations to mitigate plasma interactions with the signals. Second, two optical pyrometers are sighted onto the cathode surfaces. An infrared (IR) thermometer is sighted onto the cathode body tube, immediately upstream of the orifice plate weld (nearly identical to the location of the downstream thermocouple). A disappearing filament (DF) optical pyrometer is sighted onto the cathode orifice plate from a window on the vacuum facility (see Fig. 7). A value of 0.39 is used for the surface emissivities parameters that is incorporated into both pyrometers. This value is a typical emissivity of a metallic, non-polished, tungsten surface at the projected operating temperatures. ${ }^{24}$ The choice of the emissivity value is somewhat arbitrary because the exact surface condition of the sighted surfaces and the time-dependence of the surface condition are unknown.

Bayard-Alpert ion gauges monitored the facility and test-port pressures. A capacitance manometer measured expellant feed-system pressure during leak-rate tests. A thermal mass flowmeter measures the xenon flow rate. All monitored parameters listed in Table 1 are recorded at 5 and 15 minute intervals by a computer during the wear-test.

\section{Vacuum Facility}

The wear-test is being performed in a cryogenicallypumped bell-jar with a xenon pumping capacity of $2100 \mathrm{~L} / \mathrm{sec}$. The test facility is shown in the photograph in Fig. 7. The hollow cathode is mounted in a $0.3 \mathrm{~m}$ diameter test port attached to the bell-jar. A 0.3 $m$ diameter pneumatic gate valve provides isolation of the test-port during equipment changes. The facility has a base pressure of approximately $1.0 \times 10^{-5} \mathrm{~Pa}$ and an operating pressure of $1.2 \times 10^{-2} \mathrm{~Pa}$ at the test conditions described below.

\section{Test Procedures}

\section{Mass Flowmeter Calibration}

The mass flowmeter was calibrated before the test on xenon with a bubble flow calibrator. A correction factor of approximately $9.0 \%$ was derived and applied to the flow rates provided in this report. No calibrations have been performed during the test in order to prevent atmospheric exposure of the cathode. A post-test calibration will be performed.

\section{Feed-system Bake-out}

Before initiation of the wear-test and after each change-out of the xenon bottle, the expellant feedsystem was heated to outgas the contaminants trapped on the interior tubing surfaces. Heat tape was wrapped over the feed-line and powered to raise the tubing temperature. The feed-system was baked out for a minimum of 24 hours and then cooled to ambient temperature before continuing.

\section{Feed-system Evaluation}

The contamination level within the expellant feedsystem was characterized by pressure-rise testing. The leak-rate of the feed-system was measured periodically throughout the wear-test to verify integrity. Similar to the wear-test results of Ref. 23 performed in the same facility, the leak-rate test behavior had no significant outgassing contribution.

\section{Feed-system Purging}

Prior to cathode activation, the feed-system was evacuated for at least 12 hours. Xenon gas was used to purge continuously for a short period at the beginning of the hollow cathode activation.

\section{Cathode Activation}

The insert was activated once the test port was at a facility pressure of at least $1.3 \times 10^{-4} \mathrm{~Pa}$ and feed-line pressure was below $1.0 \times 10^{-2} \mathrm{~Pa}$. The procedure used at NASA-LeRC was derived from an activation procedure developed during the SEPS program. ${ }^{25}$ This multiple step procedure was similar to the procedure used in previous wear-tests. ${ }^{18,23}$ The same activation procedure was performed after each of the 9 discharge shutdowns during the test where exposure of the cathode to atmospheric gases was suspected. After activation, a short, high-temperature pre-heat of the cathode was performed to enable low-voltage ignition of the discharge.

\section{Wear-test Performance}

\section{Wear-test Set Point}

The target operating set point is a steady-state emission current of $12.0 \mathrm{~A}$ and a xenon flow rate of 7.6 $\mathrm{Pa}-\mathrm{L} / \mathrm{s}(4.5 \mathrm{sccm}$ or $0.41 \mathrm{mg} / \mathrm{s})$. The $12.0 \mathrm{~A}$ set point selection was driven by the maximum current requirement set forth at the time. ${ }^{2}$ The xenon flow rate setting provided discharge stability and maintained the discharge voltage at less than $20.0 \mathrm{~V}$, which was the upper limit of operation allowed by ISSA 
requirements. ${ }^{2}$ The test was initiated on December 30 , 1992. Table 2 includes the initial and nominal values of each parameter.

\section{Wear-test Chronology}

The dependent operating paramters of the cathode are the discharge voltage and the temperatures. Changes in these parameters reflect changes in cathode condition and consequently are expected to provide the best indicators of cathode health. Figure 8 shows the behavior of the discharge voltage as a function of test time. Two types of voltage variations have been observed. First, the discharge voltage varied erratically over periods of thousands of hours from a maximum voltage of $15.1 \mathrm{~V}$ to a minimum of $10.9 \mathrm{~V}$. Insufficient data are available at this time to explain these longperiod varations, however, the changes are relatively small, as can be seen in Fig. 8. At the time of writing, the nominal value of the discharge voltage was $12.9 \pm$ $0.6 \mathrm{~V}$ after 10,000 hours of operation. Second, variations due to changes in xenon flow rate occurred on a daily period. These flow rate changes are typically about $\pm 5 \%$ and are believed to be the result of daily variations in ambient temperature, changes in the xenon pressure behavior in the feed-line, and the resolution limits of the flow metering valve.

Cathode tube temperatures as a function of test time are shown in Figs. 9 and 10. Figure 9 shows the temperature measurements from the three thermocouples attached to different locations on the cathode body tube. The temperatures at all three locations have decreased monotonically at somewhat different rates during the test. The cathode tip temperature (T/C 1) decreased from the maximum temperature of $1115^{\circ} \mathrm{C}$ at the beginning of this test to a minimum temperature of $1022^{\circ} \mathrm{C}$ by hour 6947 . At that time, the thermocouple detached from the cathode tube and could no longer provide meaningful data. $\mathrm{T} / \mathrm{Cs} 2$ and 3, mounted upstream of the cathode heater, exhibited approximate decreases of 107 and $44{ }^{\circ} \mathrm{C}$, respectively, and have remained attached to the cathode tube. The thermocouples have a measurement accuracy of $1 \%$, however, there may be additional errors introduced by plasma interactions. Neglecting plasma effects, the error in temperatures will still be of the same order as the measured temperature changes in each of the locations during the test, as can be seen by examining the nominal temperatures in Table II. Insufficient data are available to determine if the temperature changes observed to date are real, however, the pyrometer data to be discussed below have provided different results, indicating that the observer changes may be measurements arifacts.

The 'noise' in all the temperature measurements is the result of the daily variations in xenon flow rate. Additionally, the temperature 'spike' indicated at approximately 1500 hours was the result of off-normal behavior experienced immediately prior to discharge shut-down.

Figure 10 shows the temperature behavior as measured by the two pyrometers. While not in agreement quantitatively, the temperature behaviors for both the DF pyrometer and IR thermometer exhibited similar long-term behavior. The cathode tip temperature has decreased monotonically during the first 7000 hours of the test from maximum temperatures of $1355^{\circ} \mathrm{C}$ and $1225^{\circ} \mathrm{C}$ for the DF pyrometer and IR thermometer, respectively. The minimum temperatures measured were $1218^{\circ} \mathrm{C}$ and $1058{ }^{\circ} \mathrm{C}$ for the DF pyrometer and IR thermometer respectively. Since the temperatures stopped decreasing, they have risen slightly to maximums at about hour 8500 and appear to be decreasing again. The nominal cathode tip temperatures at the time of this report are $1255^{\circ} \mathrm{C} \pm 21{ }^{\circ} \mathrm{C}$ and $1178^{\circ} \mathrm{C} \pm 27^{\circ} \mathrm{C}$ for the DF pyrometer and IR thermometer respectively. The measured temperatures shown in Fig. 10 exhibit short-term noise that was the results of daily variations in cathode operation. This short-term noise has apparently increased since hour 7300 (shut-down \#8), but no explanation for the increase can be offered at this time.

The differences in measurements between the DF pyrometer and the IR thermometer is attributed to the different sighting locations and paths, as well as unavoidable changes in pyrometer positions. From experience with these devices on this and earlier tests, the DF pyrometer has an overall uncertainty of $\pm 25^{\circ} \mathrm{C}$ and the IR thermometer has a sighting repeatability of $\pm 50{ }^{\circ} \mathrm{C}$ and a focusing repeatability of $\pm 50^{\circ} \mathrm{C}$. Additionally, the true surface emissivity of the surfaces measured are unknown. No compensation for changes in the surface emissivity during the wear test due to changes in the surface condition is employed.

Initially, the thermocouples were used at the primary source for cathode temperature information and the pyrometers were used as references to check thermocouple behavior. However, since the loss of the cathode tip thermocouple, the DF pyrometer measurements have been used for the characterization of cathode performance, including qualitative indications of performance degradation. Confidence in the use of the DF pyrometer measurements is derived from the qualitatively consistent agreement in temperature behavior that existed between measurement techniques prior to detachment of the cathode tip thermocouple.

Dynamic behavior of the discharge voltage and emission current signals are monitored with an oscilloscope throughout the test. The emission current noise level has remained relatively constant at a nominal value of $0.12 \%$ during the test. The discharge voltage noise is more erratic, but never exceeded $1 \%$ throughout the wear-test. The average voltage noise is 
$0.72 \%$. The dynamic behavior for discharge voltage has been random to date, and the current noise has consisted of a random component and a component at approximately $250 \mathrm{~Hz}$. The cause of this $250 \mathrm{~Hz}$ signal is not known at this time.

\section{Parametric Characterization}

Cathode operation has been characterized over the course of the test by measuring the discharge voltage and cathode temperatures under variation of emission current and xenon flow rate. Figure 11 shows the behavior of the discharge voltage as a function of emission current. All data were taken at a fixed xenon flow rate of $7.6 \mathrm{~Pa}-\mathrm{L} / \mathrm{s}(4.52 \mathrm{sccm}$ or $0.41 \mathrm{mg} / \mathrm{s})$. As can be seen, the discharge voltage behavior is relatively constant throughout the test. Variations are largest in the 6-9 A range, as the discharge voltage at $8.0 \mathrm{~A}$ has increased by approximately $38 \%$ during the test. At the wear-test point of $12.0 \mathrm{~A}$, all voltages are within $5.5 \%$ of the mean value of $11.6 \mathrm{~V}$. Table 3 shows the chronology of the data sets indicated in Fig. 11. Not indicated in Table 2 is the initial data set which was taken before the life test.

Figure 12 shows the cathode tip temperature behavior as a function of emission current at a fixed xenon flow rate of $7.6 \mathrm{~Pa}-\mathrm{L} / \mathrm{s}$ measured with the $\mathrm{DF}$ pyrometer. The cathode temperature exhibits a monotonic increase with emission current, rising by approximately $439^{\circ} \mathrm{C}$ with a $10 \mathrm{~A}$ increase in emission current. The cathode temperature exhibited small changes in behavior during the test, as the temperature decreased slightly after the pre-test measurements. However, the observed changes were on the order of the measurement uncertainty of $\pm 25 \mathrm{~V}$ and therefore preclude making any definite conclusions at this time. While not shown here, the IR pyrometer data exhibited similar behavior. As with discharge voltage, the different data sets have been taken over the course of the wear-test at times noted in Table 2.

Figure 13 shows the discharge voltage as a function of the xenon flow rate. Emission current is fixed at 12.0 A. The data exhibits the largest variation at flow rates below $8.0 \mathrm{~Pa}-\mathrm{L} / \mathrm{s}$. At the wear-test flow rate, the discharge voltage increased by approximately $16.6 \%$ from the pre-test data set to the data set taken at shutdown \#4, then decreased to within $5 \%$ of the initial discharge voltage by the time of shutdown \#9.

Figure 14 shows the cathode tip temperatures versus xenon flow rate as measured by the DF pyrometer. All data are taken with a fixed emission current of $12.0 \mathrm{~A}$. The cathode temperature exhibited the greatest sensitivity to xenon flow at the beginning of the life test, as the tip temperature increased by $107^{\circ} \mathrm{C}$. By hours 4772 and 10001 , the temperature changed by only $42{ }^{\circ} \mathrm{C}$ and $55^{\circ} \mathrm{C}$ over the same flow rate range. Insufficient data are available to verify the cause of the temperature decrease. The cathode temperature behavior has remained relatively constant, within the accuracy of the DF pyrometer, for all data taken after the start of the test.

\section{Ignition Characteristics}

In all instances, the discharge has been established or re-established using the steady-state applied voltages of the discharge supply, without having to resort to a high voltage pulse. The voltage is raised gradually until breakdown occurred. Table 4 lists the required ignition voltages over the course of the test. The average ignition voltage is $41.8 \pm 2.2 \mathrm{~V}$ during the 9 discharge starts to date.

\section{Wear-test Shut-downs}

Nine test shut-downs have occurred to date. The chronology of the shut-downs along with the suspected or known causes is listed in Table 3. The first shutdown was believed to be the result of a faulty pressure sensor that caused an unintentional closing of the isolation valve between the test port and the facility. The discharge continued to operate for 10.5 hours within the test port as the local pressure rose to approximately $25 \mathrm{~Pa}$. The discharge voltage and cathode tip thermocouple temperature rose to maximum values of $18.8 \mathrm{~V}$ and $1170^{\circ} \mathrm{C}$, respectively, during this time. After this shut-down, the suspect sensor was replaced, a pressure interlock was added; the xenon bottle was changed out, and the cathode was reactivated and reignited. As can be seen in Figure 8, the discharge voltage was initially lower than before shut-down, but recovered quickly.

Shut-downs \#2, 6, 7, 9 and 10 were due to building power loss and resulted in discharge power supply and vacuum facility shut-down. Afterwards, the cathode was reactivated and reignited. Cathode operation resumed with negligible change in discharge voltage and temperatures.

Shut-down \#3 was again believed to be the result of a faulty pressure sensor and resulted from an unintentional closure of the main isolation valve. The discharge was immediately shut off as a result. Subsequently, the cathode was reactivated and reignited and resumed operation with negligible change in operating parameters.

Shut-downs \#4, 5, and 8 were intentional to replenish the xenon gas supply. After the gas bottle was changed and the feed-system slightly modified for pump-out, the cathode was again reactivated and reignited.

\section{Discussion of Performance}

In preparation for this wear-test, numerous modifications and procedures to mitigate contamination of the cathode were implemented. The test configuration incorporated all the system 
improvements used in an earlier, successful, 500-hour hollow cathode wear-test. ${ }^{23}$ These improvements included active purification of the xenon expellant stream; pre-test feed-system bake-out to remove interior surface contaminants; and use of ultra high vacuum fittings, valves, and transducers in the expellant feed-system. Feed-system integrity has been maintained throughout the wear-test.

The behaviors of three parameters are of primary interest. First, the discharge voltage has not varied from a nominal value of $12.9 \mathrm{~V}$ by more than $3.1 \mathrm{~V}$ for over 10,000 hours. Additionally, the discharge voltage behavior under variation of emission current and xenon flow rate has remained approximately constant.

Second, the average cathode tip temperature has remained relatively constant over the course of the life test. It should be noted that the qualitative behavior of the pyrometer measurements is being used as an indicator of cathode condition, but not as a highly accurate measurement of cathode temperature. A type $R$ thermocouple had been used to more accurately measure the cathode temperature, but the loss of the thermocouple at hour 6947 required that the DF pyrometer temperature measurements be relied on to monitor cathode condition. As shown in Figure 9, the thermocouple measurements exhibited a monotonic decrease with time that, in an earlier report ${ }^{26}$ was speculated to be caused by changing radiation losses of the cathode due to changes in surface conditions. It now appears as if the decreases are more likely the result of the degradation of the spot-welds holding the thermocouples in place. Post-test examination of the cathode should reveal the correct cause of the temperature variations.

Finally, cathode ignition voltages have remained nearly constant during the several restarts that have occurred during this test. Increased ignition voltages have been associated with deteriorating cathode condition in previous extended tests. ${ }^{17-19}$ Consequently, the stable ignition voltage suggests that the internal cathode condition has remained relatively constant during this test. Further analyses of the cathode condition will wait until completion of the wear-test.

\section{Summary Remarks}

An on-going hollow cathode life test has operated successfully for more than 10000 hours in a planar diode configuration at a steady-state emission current of $12.0 \mathrm{~A}$ and xenon flow rate of $7.5 \mathrm{~Pa}-\mathrm{L} / \mathrm{s}(4.5 \mathrm{sccm})$. The cathode has operated at a nominal discharge voltage of $12.9 \mathrm{~V}$ and an average cathode tip brightness temperature of $1255^{\circ} \mathrm{C}$. The cathode has experienced 10 shutdowns, both intentional and unintentional, during the wear-test. In all cases, pre-shutdown performance recovered after reactivation and reignition. The cathode has ignited at an average voltage of $42.0 \mathrm{~V}$ in ten instances over the course of the wear-test. This wear-test of a xenon hollow cathode at high (>1.0 A) emission current represents the longest reported test exceeding 1,000 hours that has not suffered from performance and life degradation due to cathode contamination.

\section{Acknowledgments}

The author would like to acknowledge the technical support of F.K Jent, J.R. Miller, G.R. Schneider, R.D. Buttler, C.D Schroeder, J.B. Naglowsky, and J.E. Parkes in execution of this wear-test.

\section{References}

${ }^{1}$ Moorehead, R.W., Deputy Director, Space Station Freedom Program and Operations, communication to Work Packages 1-4 Directors, dated April 3, 1992.

${ }^{2}$ Patterson, M.J., Hamley, J.A., Sarver-Verhey, T.R., Soulas, G.C., Parkes, J.E., Ohlinger, W.L., Schaffner, M.S., and Nelson, A., "Plasma Contactor Technology for Space Station Freedom," AIAA Paper 93-2228, June 1993.

${ }^{3} \mathrm{Kohl}$, W.H., Handbook of Materials and Techniques for Vacuum Devices, Reinhold, New York, 1967, pp. 491-496.

${ }^{4}$ Kerslake, W.R. and Ignaczak, L.R., "Development and Flight History of SERT II Spacecraft," Journal of Spacecraft and Rockets, Vol. 30, No. 3, May-June 1993, pp. 258-290.

5 Anon., "8-cm Mercury Ion Thruster System Technology," NASA TM X-71611, Oct. 1974.

${ }^{6}$ Collett, C. and Power, J.L., "Qualification Test Results of IAPS $8 \mathrm{~cm}$ Ion Thrusters," AIAA Paper 821954, Nov. 1982.

${ }^{7}$ Anon., "30-cm Ion Thrust Subsystem Design Manual," NASA TM-79191, April 1980.

8Stewart, D., "Life-Testing of the UK T4A Thruster," AIAA Paper 76-1023, Nov. 1976.

${ }^{9}$ Krulle, G., Zeyfang, E., and Voit-Nitschmann, R., "Recent Life and Performance Test Results Achieved Within the RIT-10 D \& Q Program," AIAA Paper 78678, April 1978.

${ }^{10}$ Kitamura, S., Nagano, H., Nakamura, Y., Kudo, I., and Machida, K., "ETS-III Ion Engine Flight Operations in the Extended Mission Period," Journal of Propulsion and Power, Vol. 2, No. 6, Nov.-Dec. 1986, pp. 513-520.

${ }^{11}$ Collett, C., "Thruster Endurance Test," NASA CR135011 , May 1976.

${ }_{12}$ Bechtel, R.T., Trump, G.E., and James, E.J., "Results of the Mission Profile Life Test," AIAA Paper 82-1905, Nov. 1982. 
${ }^{13}$ Ramsey, W.D., "12-cm Multi-Cusp Ion Thruster Inert Gas Performance," NASA CR-168208, July 1984.

${ }^{14}$ Beattie, J.R., Matossian, J.N., and Robson, R.R., "Status of Xenon Ion Propulsion Technology," AIAA Paper 87-1003, May 1987.

${ }^{15}$ Brophy, J.R. and Garner, C.E., "Tests of High Current Hollow Cathodes for Ion Engines," AIAA Paper 88-2913, July 1988.

16Rawlin, V.K., "Internal Erosion Rates of a $10 \mathrm{~kW}$ Xenon Ion Thruster," AIAA Paper 88-2912, July 1988.

17Patterson, M.J. and Verhey, T.R., "5-kW Xenon Ion Thruster Life-test," AIAA Paper 90-2543, July 1990.

${ }^{18}$ Sarver-Verhey, T.R. and Patterson, M.J., "Microanalysis of Extended-Test Xenon Hollow Cathodes," AlAA Paper 91-2123, June 1991.

${ }^{19}$ Brophy, J.R. and Garner, C.E., "A 5,000 hour Xenon Hollow Cathode Life Test," AIAA Paper 912122, June 1991

${ }^{20}$ Kitamura, S., Miyazaki, K., and Hayakawa, Y., "Cyclic Test of a $14 \mathrm{~cm}$ Diameter Ring-Cusp Xenon Ion Thruster," AIAA Paper 92-2146, July 1992.
${ }^{21}$ Shimada, S., Satoh, K., Gotoh, Y., Nishida, E., Noro, T., Takegahara, H., Nakamaru, $K$., and Nagano, H., "Ion Thruster Endurance Test Using Development Model Thruster for ETS-VI," IEPC Paper 93-169, Sept. 1993.

${ }^{22}$ Soulas, G.C., "Multiple Hollow Cathode Wear Testing for the Space Station Plasma Contactor," AIAA Paper 94-3310, Jume 1994.

${ }^{23}$ Sarver-Verhey, T.R., "Extended-Testing of Xenon Ion Thruster Hollow Cathodes," NASA CR 189227, July 1992.

${ }^{24}$ Reick, G.D., Tungsten and Its Compounds, Pergamon Press, Oxford, 1967, pp. 22-23.

${ }^{25}$ DePauw, J.F., "30 cm Thruster Cathode Activation," NASA Tech Ready Information Memo No. 13, NASA Lewis Research Center, Dec. 1977.

${ }^{26}$ Sarver-Verhey, T.R., "Extended Test of a Xenon Hollow Cathode for a Space Plasma Contactor," IEPC Paper 93-020, Sept. 1993.

Table 1 Extended Tests of Xenon Hollow Cathodes

\begin{tabular}{|c|c|c|c|c|}
\hline $\begin{array}{c}\text { Test Refernce } \\
\text { Number }\end{array}$ & $\begin{array}{c}\text { Test Duration, } \\
\text { hours }\end{array}$ & $\begin{array}{c}\text { Total Emission } \\
\text { Current, A }\end{array}$ & Test Configuration & $\begin{array}{c}\text { Problems } \\
\text { Experienced }\end{array}$ \\
\hline 14 & 4,350, steady-state & $\begin{array}{c}\text { Main }-7.4 \\
\text { Neutralizer }-3.45\end{array}$ & Ion Thurster Subsystem & $\begin{array}{l}\text { Main cathode orifice } \\
\text { closure in } 1 \text { st } 700 \text { hours }\end{array}$ \\
\hline 19 & 5,000 , steady-state & 25.0 & Ion Thruster Simulator & $\begin{array}{l}\text { Large variation in } \\
\text { discharge voltage, high } \\
\text { insert temperature, } \\
\text { orifice size increased. }\end{array}$ \\
\hline 20 & 1,960, cyclic & $\begin{array}{c}\text { Main }-3.7 \\
\text { Neutralizer }-0.5\end{array}$ & Ion Thruster & $\begin{array}{l}\text { Significant changes in } \\
\text { discharge voltage, } \\
\text { orifice size of main } \\
\text { cathode increased; } \\
\text { neutralizer replaced } \\
\text { because of ignition } \\
\text { failures. }\end{array}$ \\
\hline \multirow[t]{3}{*}{$21^{\dagger}$} & 7200 , steady-state & $\begin{array}{c}\text { Main - 3.6 A } \\
\text { Neutralizer - } 0.9 \mathrm{~A}\end{array}$ & Ion Thruster & $\begin{array}{l}\text { Large variations in } \\
\text { neutralizer voltage }\end{array}$ \\
\hline & 7100, steady-state & $\begin{array}{c}\text { Main - 3.6 A } \\
\text { Neutralizer - 0.9 A }\end{array}$ & Ion Thruster & $\begin{array}{c}\text { Neutralizer } \\
\text { performance } \\
\text { degradation due to } \\
\text { contamination, large } \\
\text { variation in neutralizer } \\
\text { voltage. }\end{array}$ \\
\hline & 8043 , cyclic & $\begin{array}{c}\text { Main - } 3.66 \\
\text { Neutralizer - } 1.0\end{array}$ & $\begin{array}{l}\text { Planar diode, both } \\
\text { cahtodes in facility }\end{array}$ & $\begin{array}{c}\text { Several ignition } \\
\text { failures, moderate } \\
\text { variations in discharge } \\
\text { voltage. }\end{array}$ \\
\hline 22 & 2,000 , steady-state & 10 per cathode & $\begin{array}{c}\text { Planar diode, } 4 \\
\text { cathodes in facility }\end{array}$ & None reported. \\
\hline
\end{tabular}

† Tests indicated are only those tests for which performance data was reported. 
Table 2 Wear-test Operating Parameters

\begin{tabular}{|c|c|c|c|}
\hline Parameter & Initial Value & Nominal Value & $\begin{array}{c}\text { Continuously } \\
\text { Monitored? (Y/N) }\end{array}$ \\
\hline Discharge Voltage, $\mathrm{V}$ & 11.0 & 12.9 & Yes \\
\hline Discharge Current, A & 12.0 & 12.0 & Yes \\
\hline Xenon Flow Rate, $\mathrm{Pa}-\mathrm{L} / \mathrm{s}(\mathrm{sccm})$ & $7.6(4.5)$ & $7.63(4.52)$ & No \\
\hline $\begin{array}{l}\text { Cathode Tip Temperature, }{ }^{\circ} \mathrm{C} \text { - } \\
\text { thermocouple }\end{array}$ & 1100 & 1022 & Yes \\
\hline $\begin{array}{l}\text { Cathode Tip Temperature, }{ }^{\circ} \mathrm{C} \text { - } \\
\text { pyrometer }\end{array}$ & 1350 & 1255 & Yes \\
\hline $\begin{array}{l}\text { Cathode Body Temperature, }{ }^{\circ} \mathrm{C} \text { - } \\
\text { thermocouple }\end{array}$ & 845 & 795 & Yes \\
\hline $\begin{array}{l}\text { Cathode Base Temperature, }{ }^{\circ} \mathrm{C} \text { - } \\
\text { thermocouple }\end{array}$ & 369 & 357 & Yes \\
\hline Discharge Current Noise, \% P-P & 0.09 & 0.72 & № \\
\hline Discharge Voltage Noise, \% P-P & 0.06 & 0.12 & № \\
\hline
\end{tabular}

Table 3 Shut-down Occurrences

\begin{tabular}{|c|c|c|c|c|}
\hline Occurrence & $\begin{array}{l}\text { Test Time, } \\
\text { hours }\end{array}$ & Cause & Modifications & $\begin{array}{l}\text { Parameters } \\
\text { Measured? }\end{array}$ \\
\hline 1 & 1467 & $\begin{array}{l}\text { Gate valve closure due to } \\
\text { faulty sensor }\end{array}$ & $\begin{array}{l}\text { Modified power system } \\
\text { interlocks. } \\
\text { Changed out Xe bottle }\end{array}$ & Yes \\
\hline 2 & 2089 & Building power loss & None & No \\
\hline 3 & 2639 & $\begin{array}{l}\text { Gate-valve closure due to } \\
\text { faulty sensor }\end{array}$ & None & No \\
\hline 4 & 3121 & $\begin{array}{l}\text { Xe supply required } \\
\text { replenishment }\end{array}$ & $\begin{array}{l}\text { Xe bottle changed. } \\
\text { Feed-system modified to allow } \\
\text { feed-line evacuation. }\end{array}$ & Yes \\
\hline 5 & 4772 & $\begin{array}{l}\text { Xe supply required } \\
\text { replenishment }\end{array}$ & Xe bottle changed & Yes \\
\hline 6 & 5415 & Building power loss & None & No \\
\hline 7 & 6947 & Building power loss & None & No \\
\hline 8 & 7305 & $\begin{array}{l}\text { Xe supply required } \\
\text { replenishment }\end{array}$ & Xe bottle changed & No \\
\hline 9 & 10001 & Building power loss & None & Yes \\
\hline 10 & 10181 & Building power loss & None & No \\
\hline
\end{tabular}

Table 4 Ignition Behavior

\begin{tabular}{cc}
\hline \hline Ignition Occurence & Voltage, $\mathbf{V}$ \\
\hline Initial Start-up & 43.5 \\
Shutdown \#1 & 45.0 \\
Shutdown \#2 & 40.5 \\
Shutdown \#3 & 39.5 \\
Shutdown \#4 & 44.0 \\
Shutdown \#5 & 43.0 \\
Shutdown \#6 & 42.2 \\
Shutdown \#7 & 39.0 \\
Shutdown \#8 & 38.0 \\
Shutdown \#9 & 42.0 \\
Shutdown \#10 & 41.5 \\
\hline \hline
\end{tabular}




\section{SARVER-VERHEY: XENON HOLLOW CATHODE EXTENDED TEST}

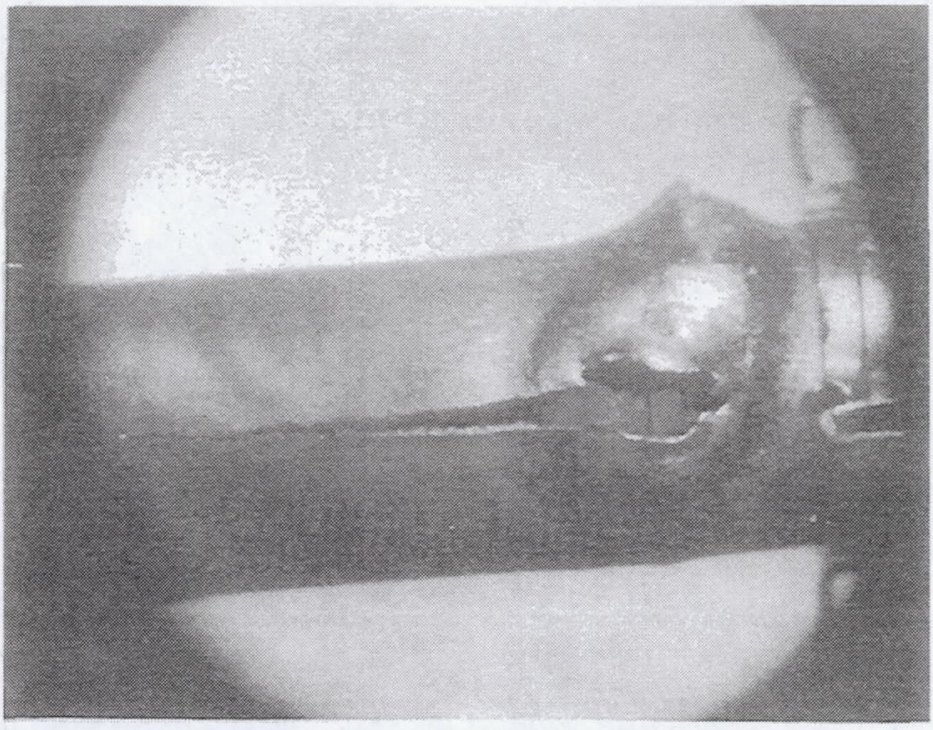

Fig. 1 Photograph of cracked tantalum cathode body tube which was damaged during a 567 hour ion thruster extended test. ${ }^{16}$

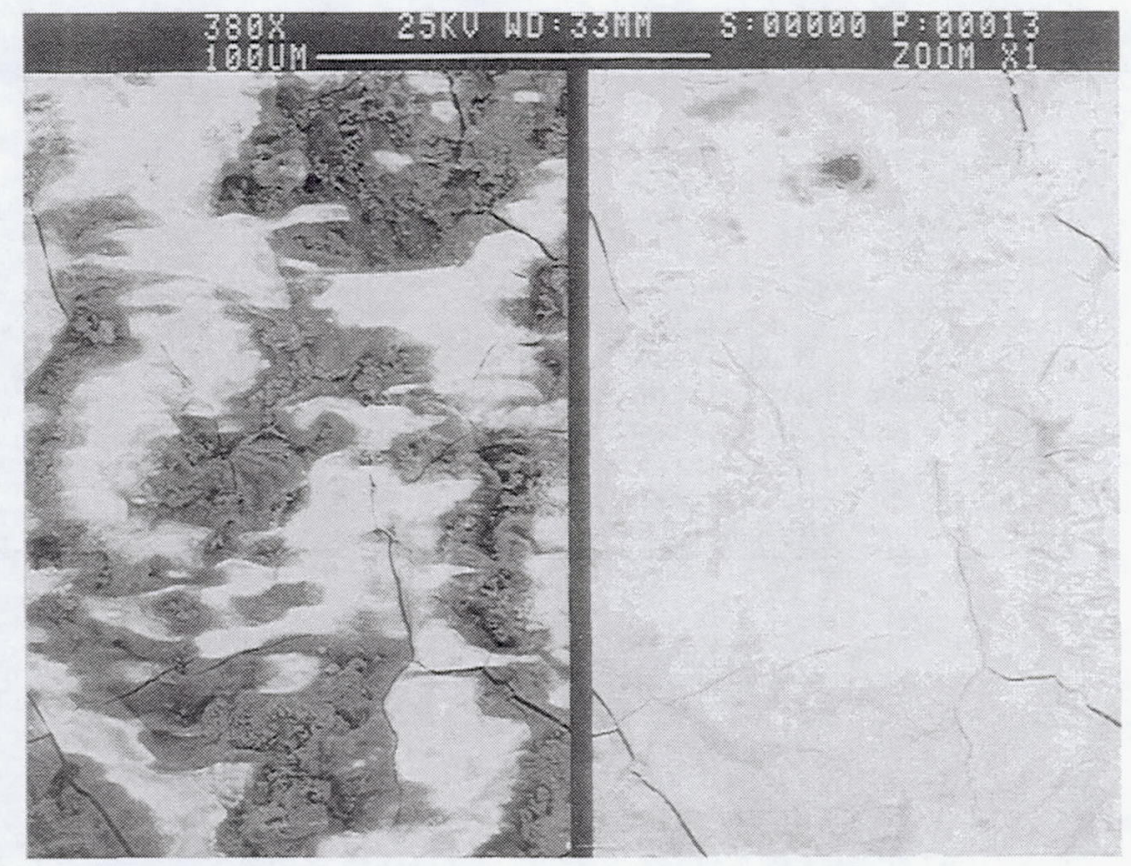

Fig. 2 Photograph of an amorphous barium-oxide material formed on cathode electron emitting insert surface during a 500 hour test. ${ }^{18}$ Left side of photo is a secondary electron emission image of the insert surface, right side is a backscattered electron emission image of the same surface. 


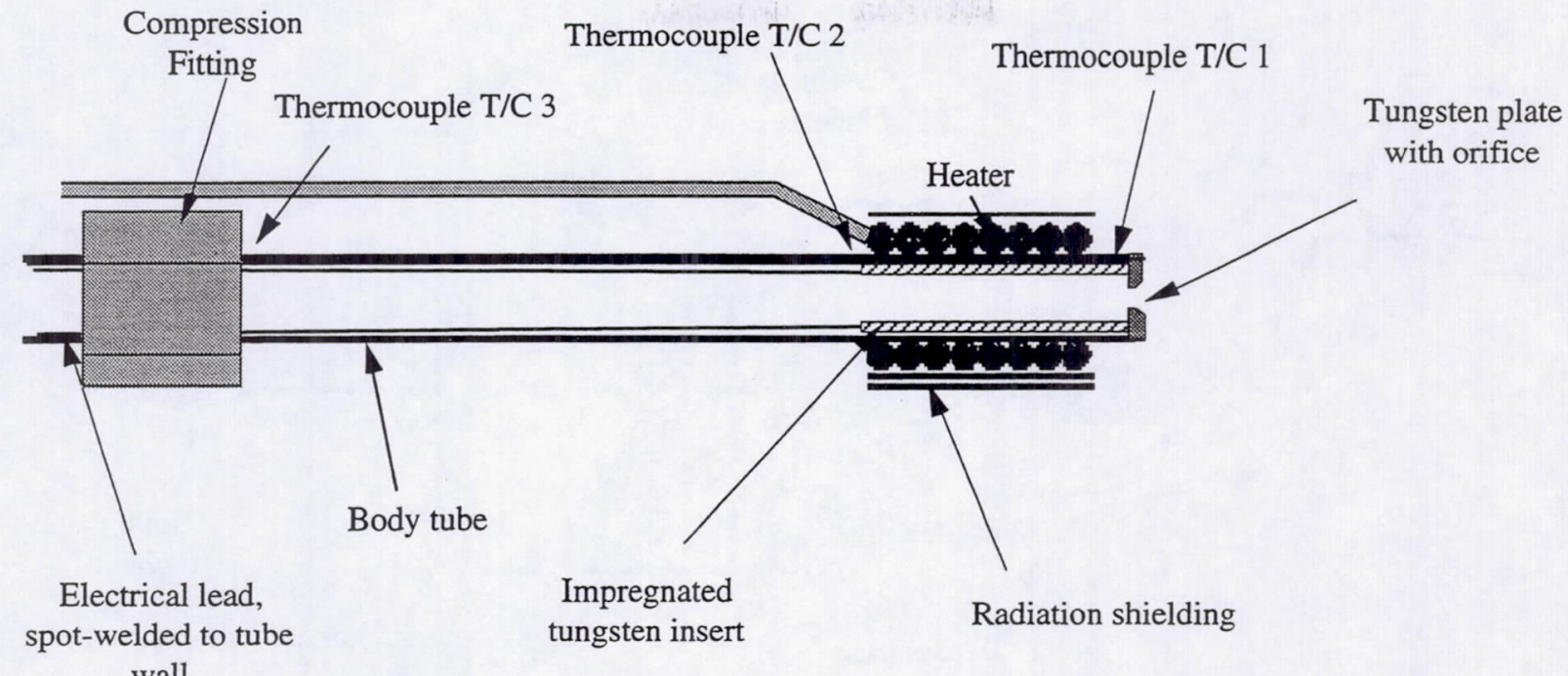

Fig. 3 Schematic of wear-test hollow cathode

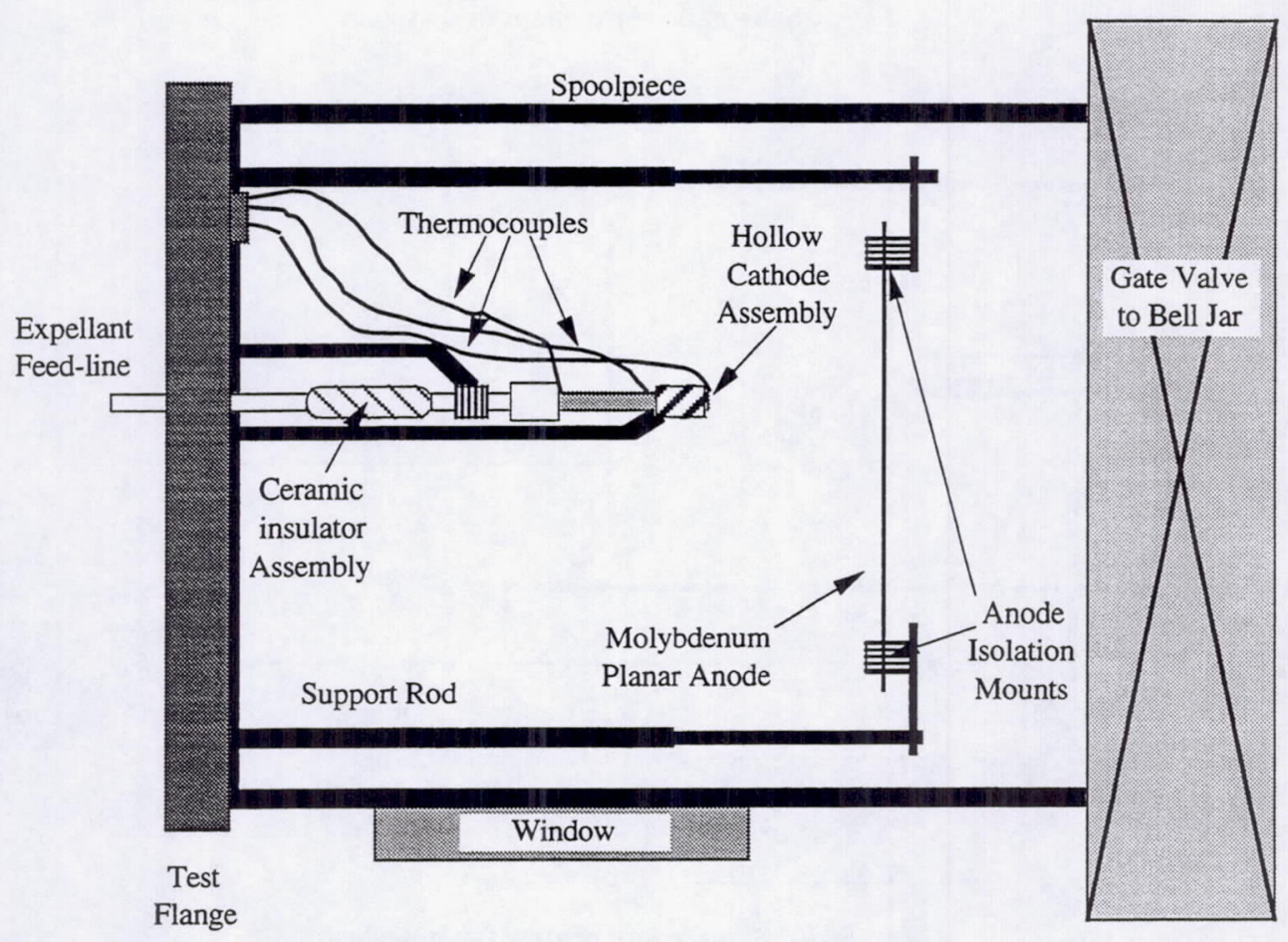

Fig. 4 Schematic of wear-test cathode/anode test configuration. 


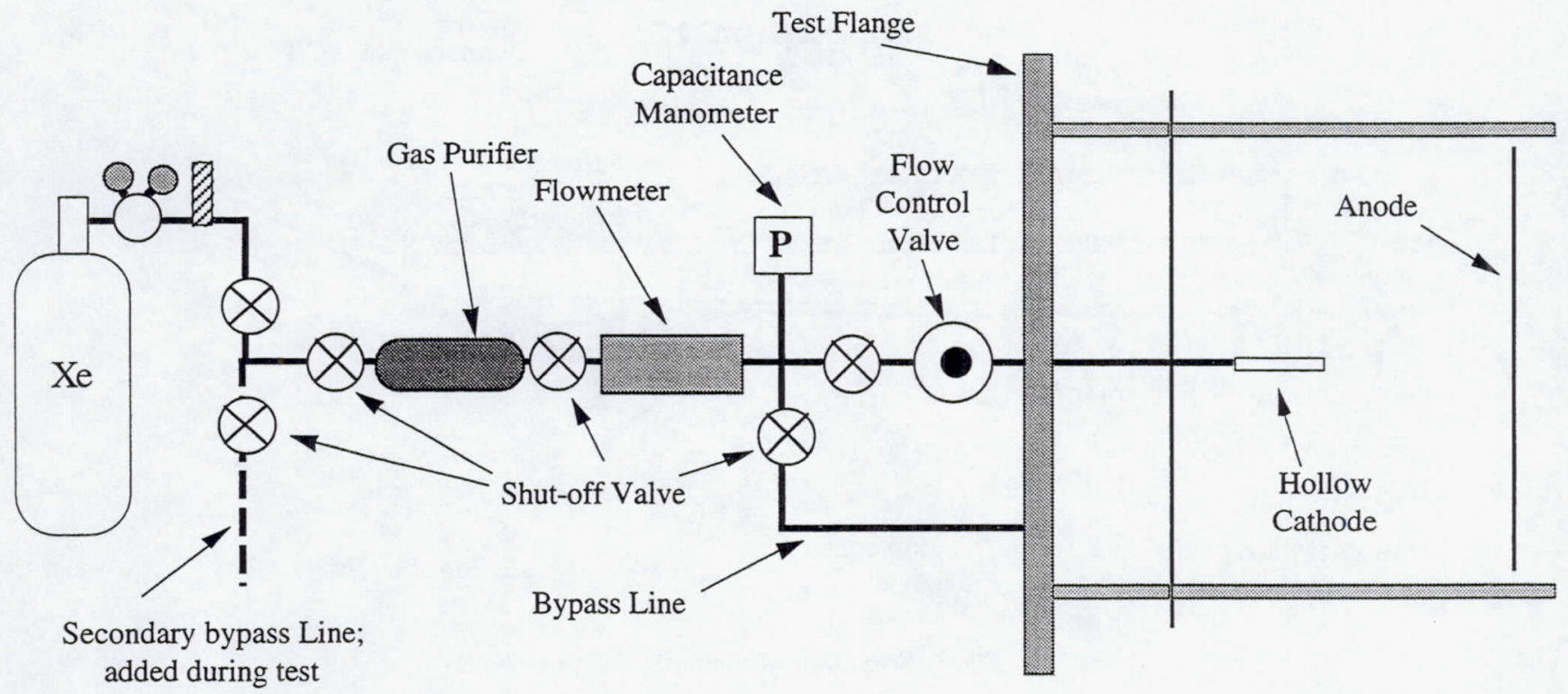

Fig. 5 Schematic of expellant feed-system

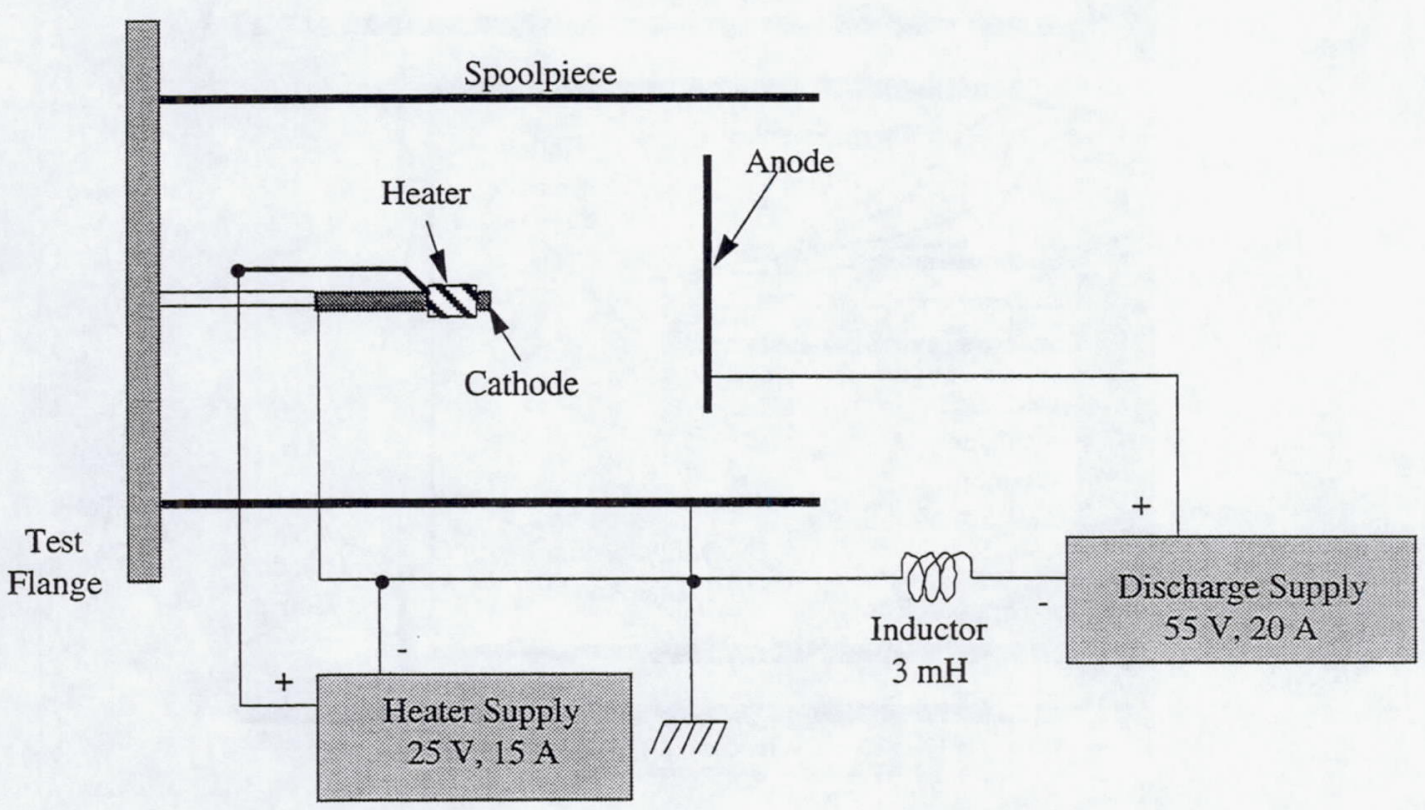

Fig. 6 Electrical configuration for wear-test. 


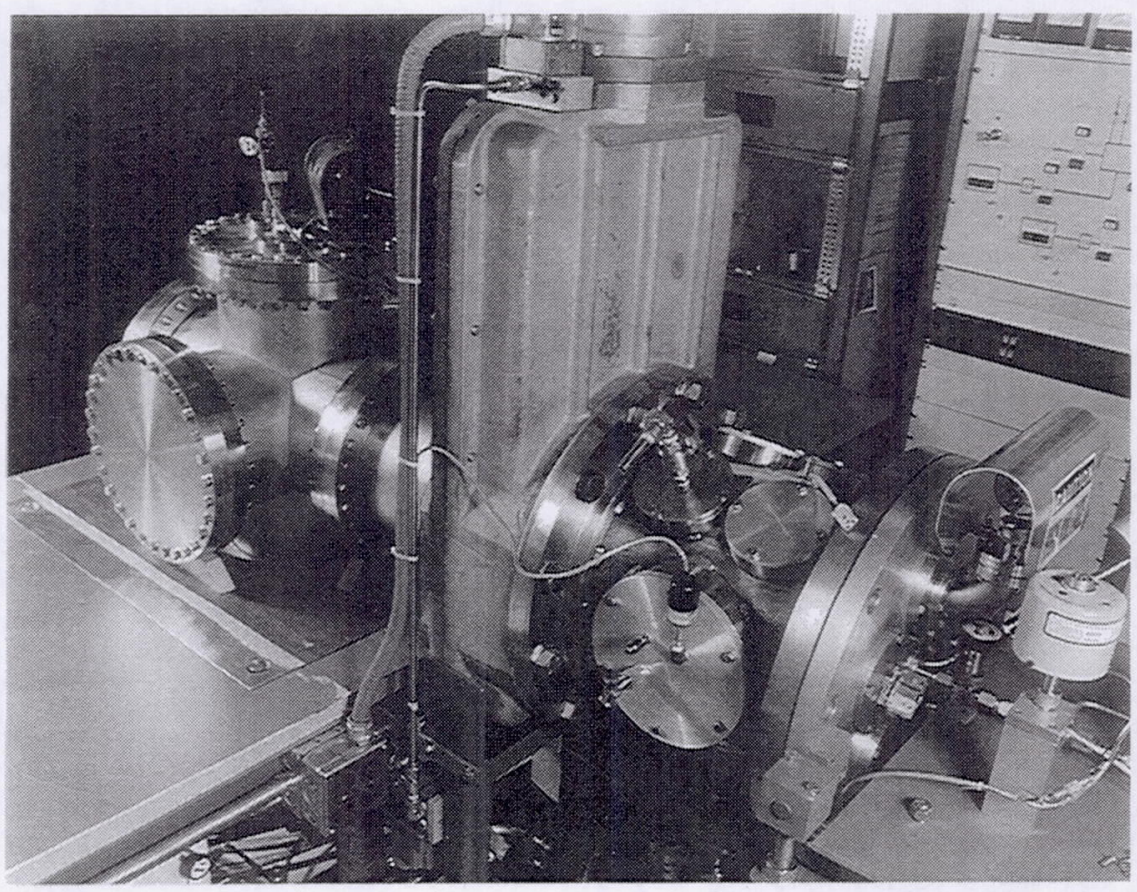

Fig. 7 Photograph of cryo-pumped vacuum facility and test-port. Test-port is on right side of photograph.

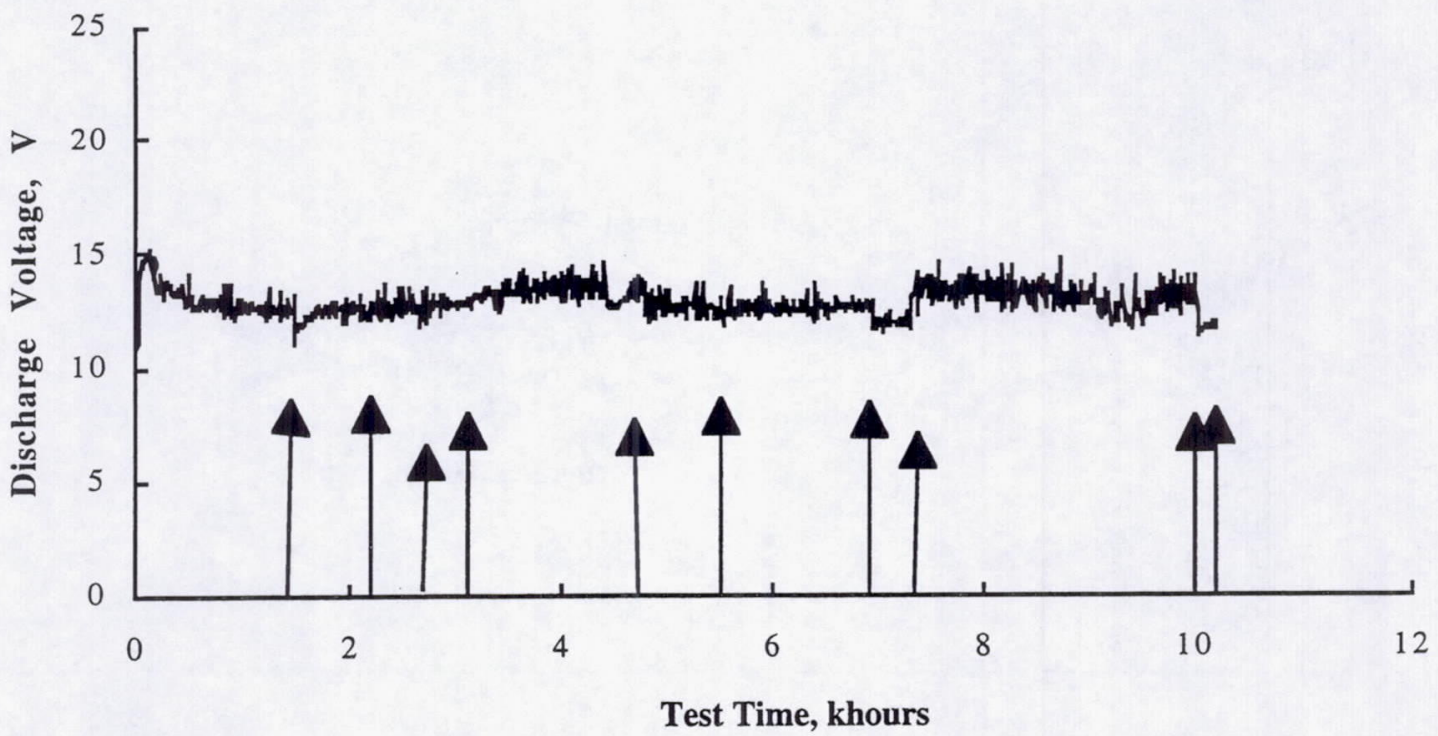

Fig. 8 Discharge voltage over course of wear-test. Emission current and xenon flow rate were fixed at 12.0 A and 7.6 Pa$\mathrm{L} / \mathrm{s}$, respectively. The vertical arrows indicate the wear-test shutdown occurences. 


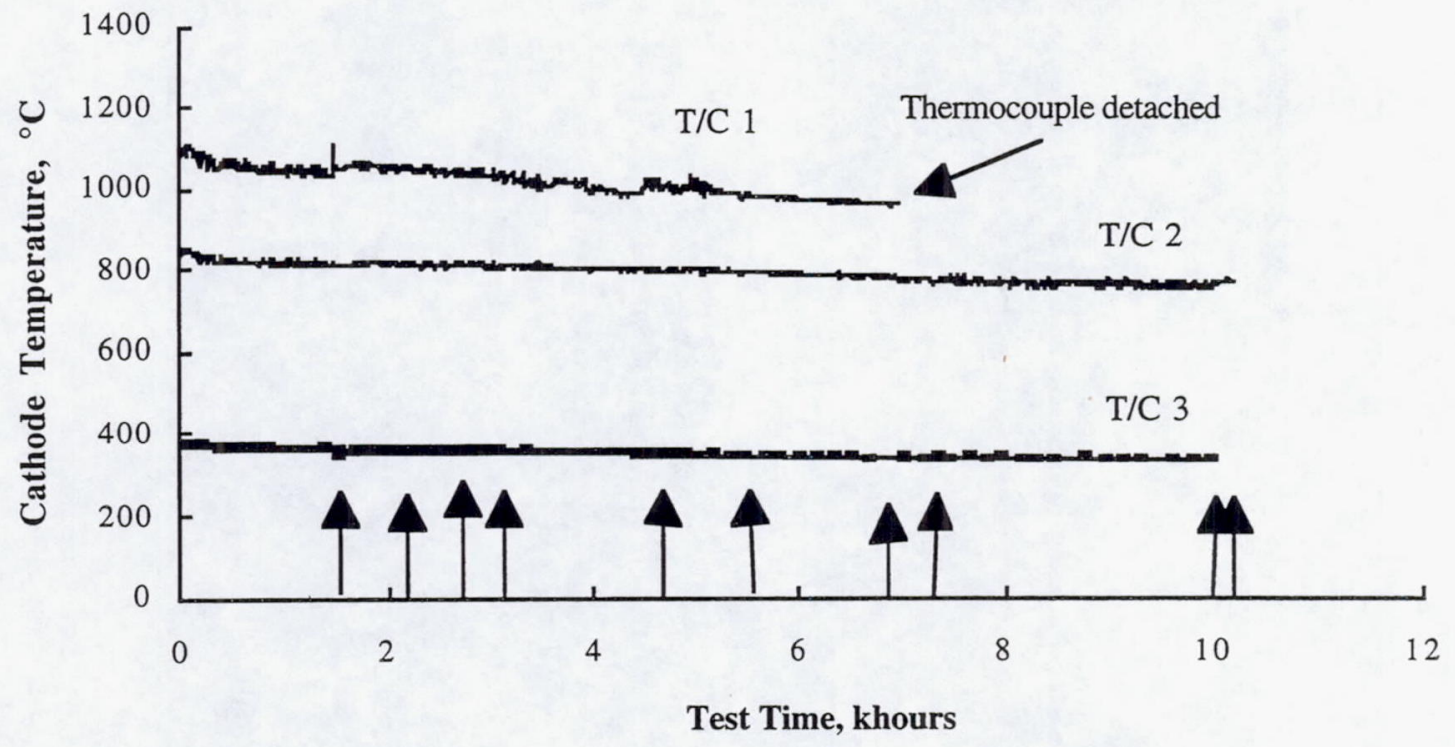

Fig. 9 Cathode thermocouple temperatures over course of wear-test.

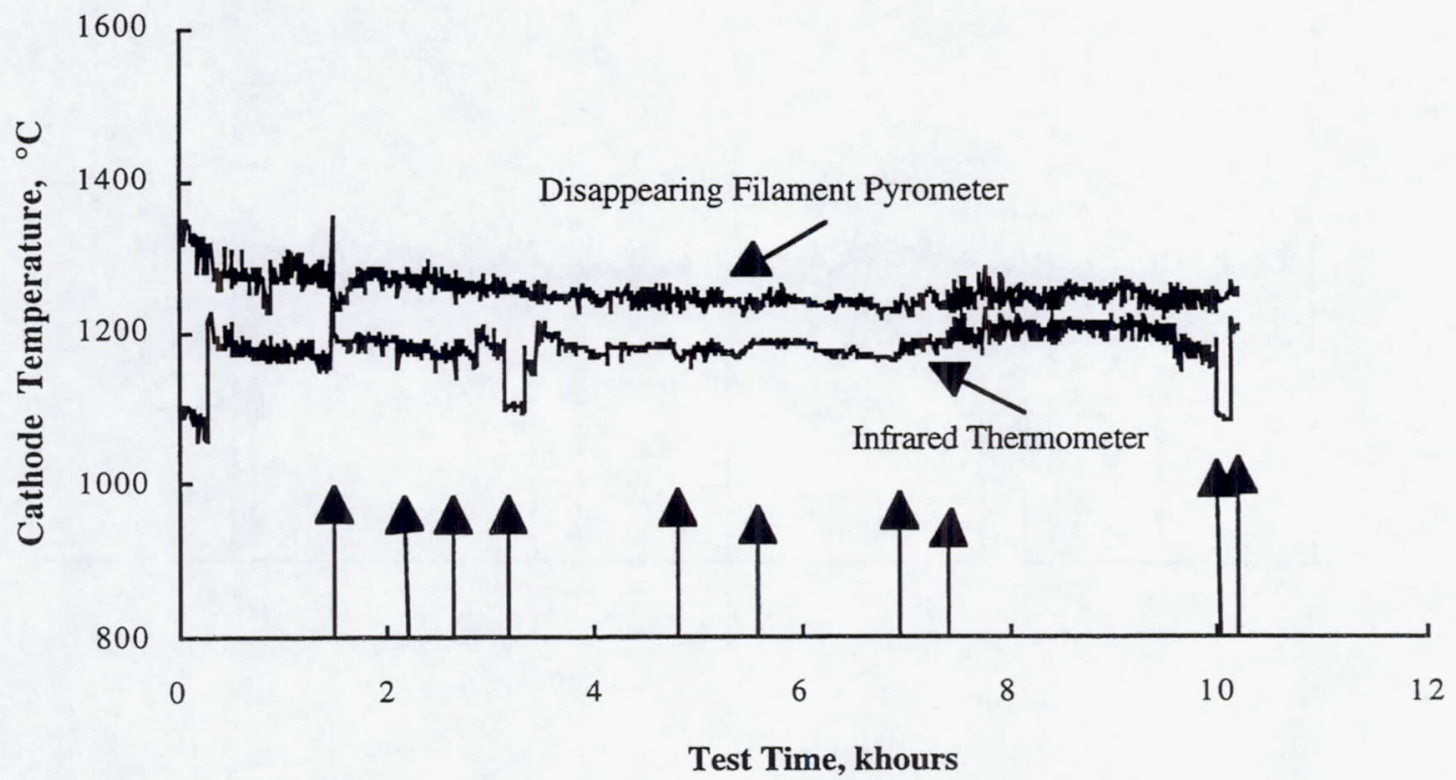

Fig. 10 Cathode pyrometer temperatures over the course of the wear-test. 


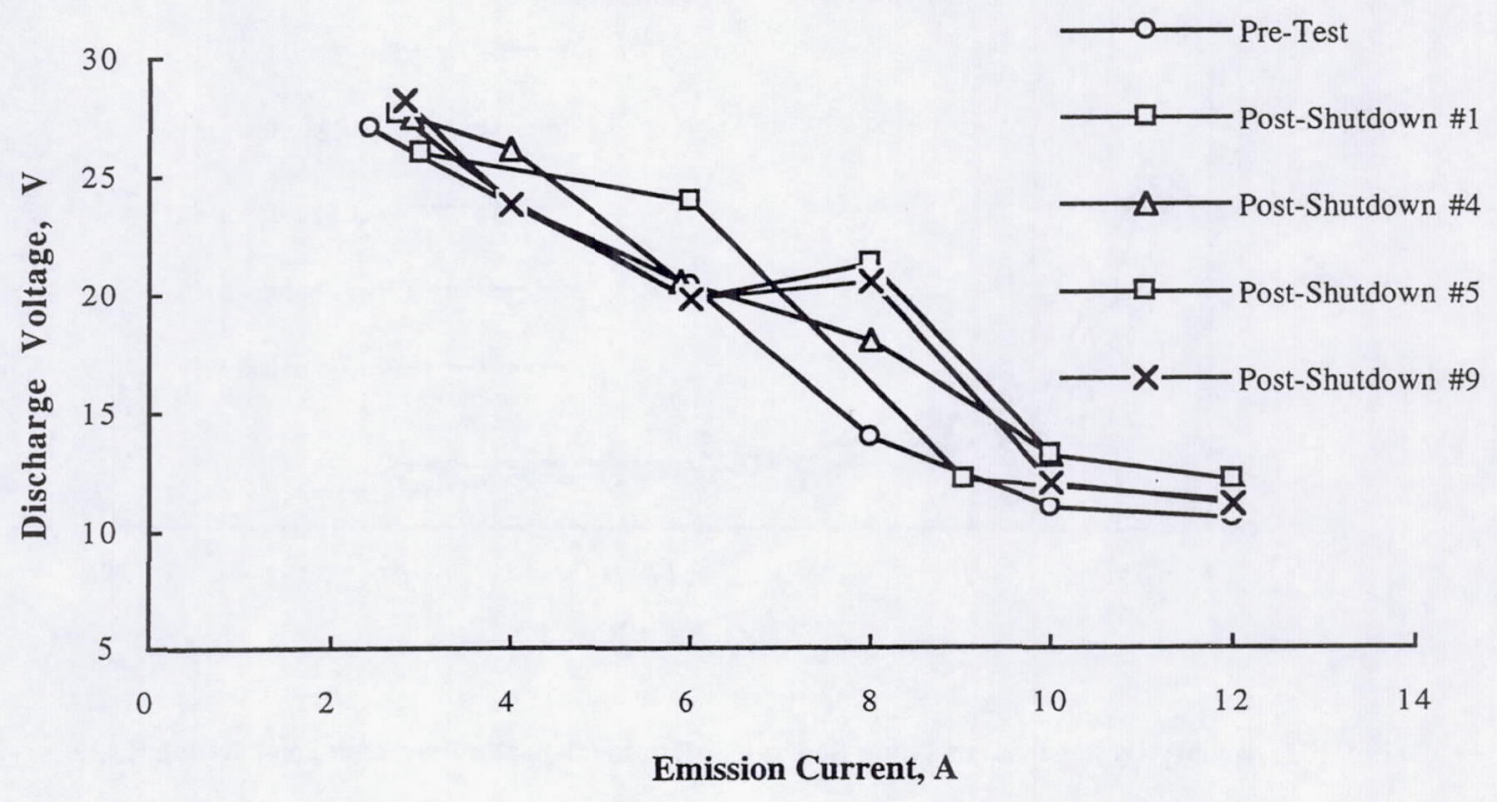

Fig. 11 Discharge voltage versus emission current. All data taken at a fixed xenon flow of 7.6 Pa-L/s.

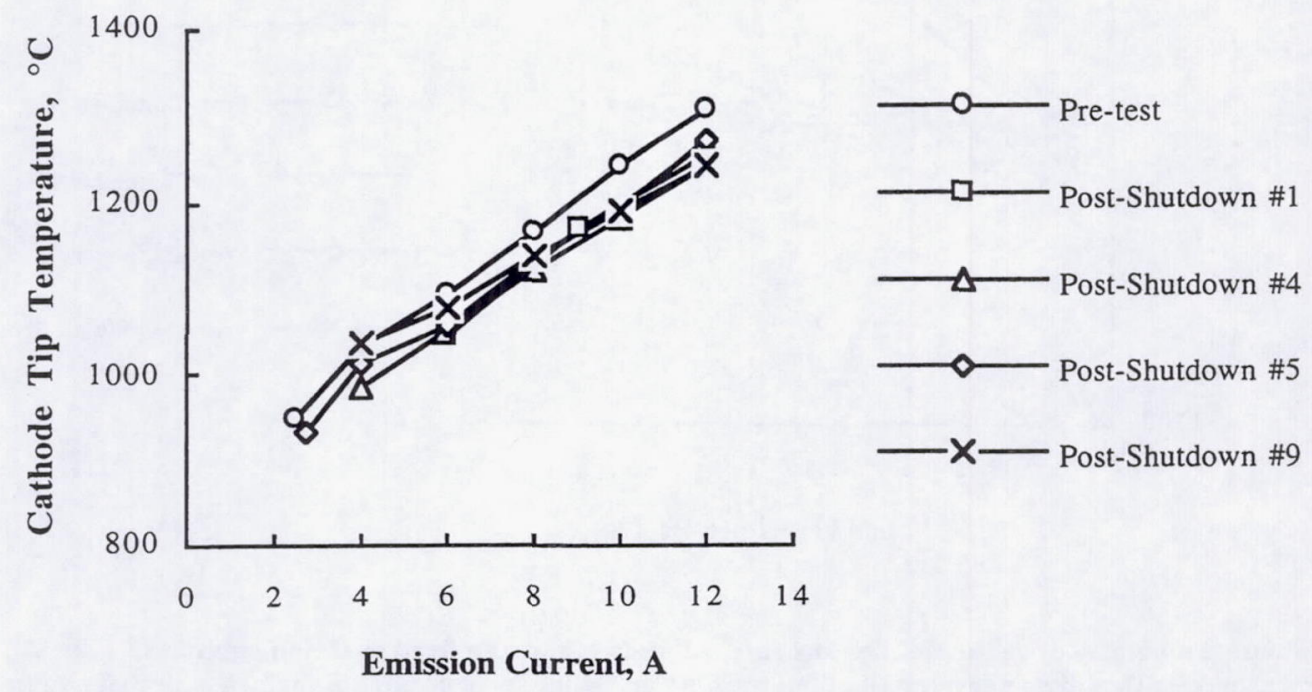

Fig. 12 Cathode tip temperatures versus emission current. All data were taken at a fixed xenon flow rate of 7.6 Pa-L/s. Temperatures were measured with a disappearring filament pyrometer, corrected for a surface emissivity value of 0.39 . 


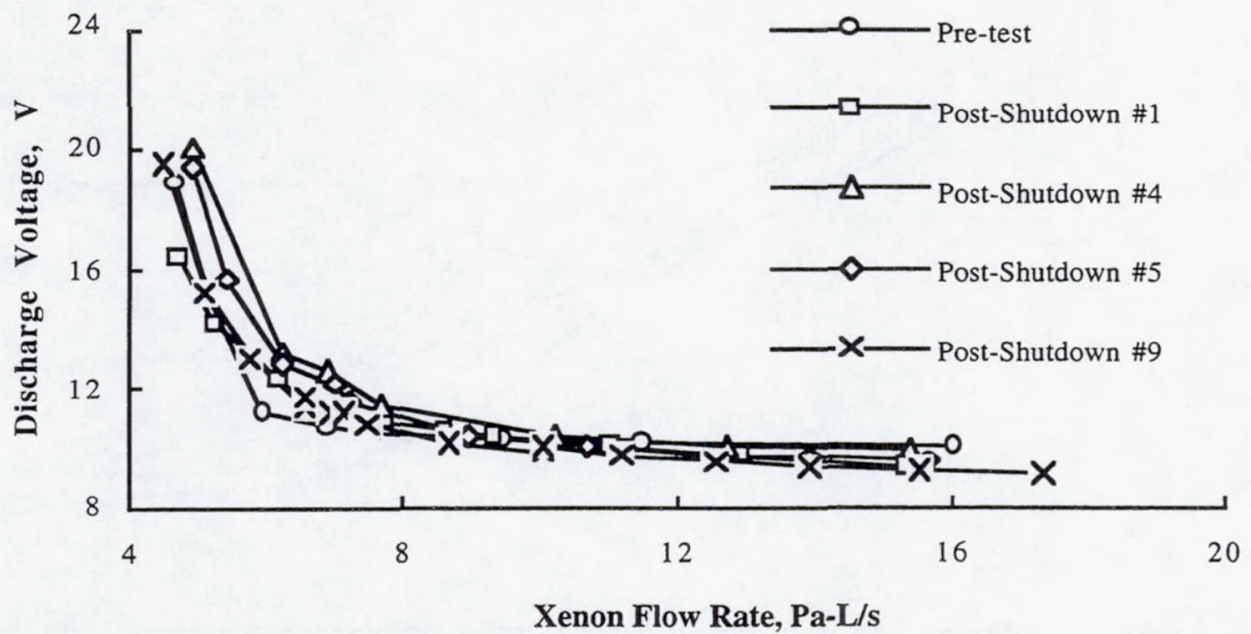

Fig. 13 Discharge voltage versus xenon flow rate. All data taken at a fixed emission current of $12.0 \mathrm{~A}$.

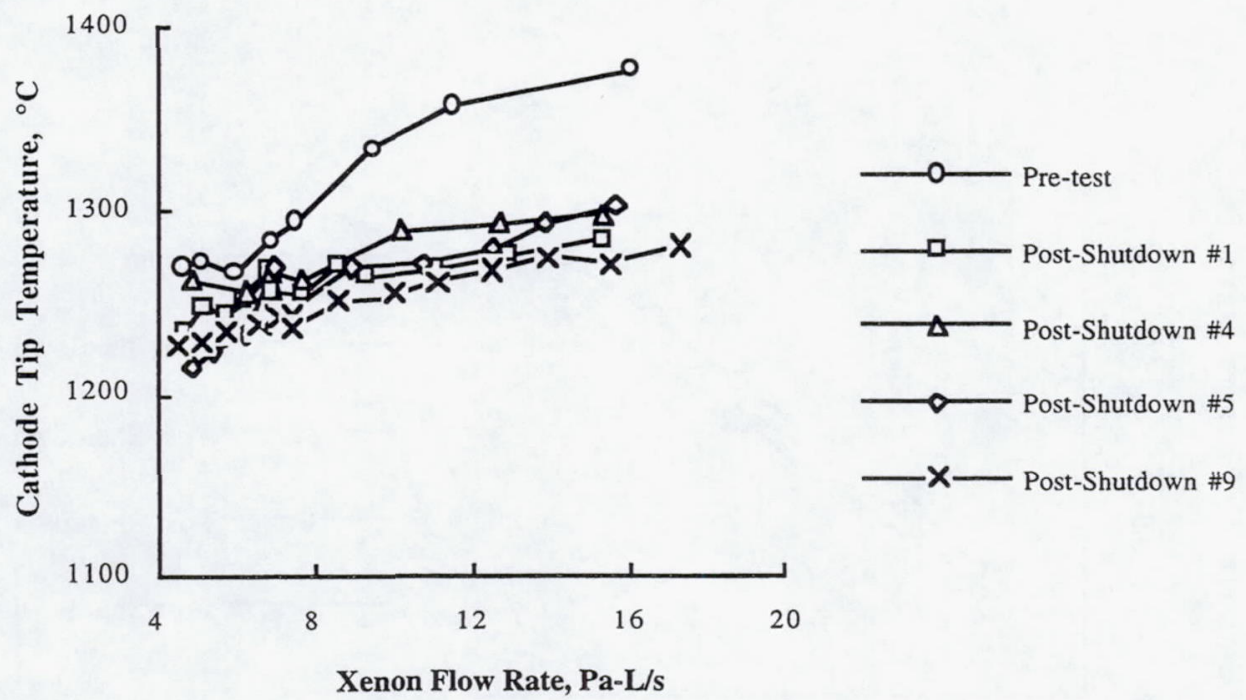

Fig. 14 Cathode temperatures versus xenon flow rate. All data taken at a fixed emission current of 12.0 A. Temperatures were measured with a disappearring filament pyrometer, which incorporated a surface emissivity value of 0.39 . 
Public reporting burden for this collection of information is estimated to average 1 hour per response, including the time for reviewing instructions, searching existing data sources,

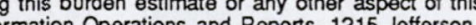
Davis Highway, Suite 1204, Arlington, VA 22202-4302, and to the Office of Management and Budget, Papenwork Reduction Project (0704-0188), Washington, DC 20503.

\begin{tabular}{|l|l|r|}
\hline 1. AGENCY USE ONLY (Leave blank) & $\begin{array}{c}\text { 2. REPORT DATE } \\
\text { November } 1994\end{array}$ & $\begin{array}{r}\text { 3. REPORT TYPE AND DATES COVERED } \\
\text { Final Contractor Report }\end{array}$
\end{tabular}

\section{TITLE AND SUBTITLE}

Continuing Life Test of a Xenon Hollow Cathode for a Space Plasma Contactor
5. FUNDING NUMBERS

WU-UPN 478-43

C-NAS3-27186

Timothy R. Sarver-Verhey

\section{PERFORMING ORGANIZATION NAME(S) AND ADDRESS(ES)}

NYMA, Inc.

Engineering Services Division

2001 Aerospace Parkway

Brook Park, Ohio 44142
8. PERFORMING ORGANIZATION REPORT NUMBER

E-9245

10. SPONSORING/MONITORING AGENCY REPORT NUMBER

NASA CR-195401

National Aeronautics and Space Administration

Lewis Research Center

Cleveland, Ohio 44135-3191

11. SUPPLEMENTARY NOTES

Prepared for the 30th Joint Propulsion Conference cosponsored by AIAA, ASME, SAE, and ASEE, Indianapolis, Indiana, June 27-29, 1994. Project Manager, Michael Patterson, Space Propulsion Technology Division, NASA Lewis Research Center, organization code 5330, (216) 433-7481.

12a. DISTRIBUTION/AVAILABILITY STATEMENT 12b. DISTRIBUTION CODE

Unclassified - Unlimited

Subject Category 20

\section{ABSTRACT (Maximum 200 words)}

Implementation of a hollow cathode plasma contactor for charge control on the Space Station has required validation of long-life hollow cathodes. A test series of hollow cathodes and hollow cathode plasma contactors was initiated as part of the plasma contactor development program. An on-going wear-test of a hollow cathode has demonstrated cathode operation in excess of 10,000 hours with small changes in operating parameters. The discharge has experienced 10 shutdowns during the test, all of which were due to test facility failures or expellant replenishment. In all cases, the cathode was re-ignited at approximately 42 volts and resumed typical operation. This test represents the longest demonstrated stable operation of a high current $(>1 \mathrm{~A})$ xenon hollow cathode reported to date.

14. SUBJECT TERMS

Xenon hollow cathode; Hollow cathode; Electron emitter; Plasma source; Plasma contactor; Spacecraft charging

17. SECURITY CLASSIFICATION OF REPORT

Unclassified

18. SECURITY CLASSIFICATION
OF THIS PAGE
Unclassified

Unclassified
19. SECURITY CLASSIFICATION OF ABSTRACT Unclassified 